\title{
РОЛЬ ВНЕДРЕНИЯ СRМ-СИСТЕМ В ПРОЦЕССЕ УПРАВЛЕНИЯ ПРЕДПРИЯТИЕМ
}

\author{
(C) 2021 Карасик Елена Анатольевна \\ кандидат экономических наук, доцент Института управления, экономики и финансов \\ Казанский федеральный университет, Россия, Казань \\ E-mail: elena-karasik2012@yandex.ru
}

(c) 2021 Карасик Олег Сергеевич аспирант

Центр перспективных экономических исследований Академии наук Республики Татарстан, Россия, Казань

E-mail:karasik_oleg@mail.ru

(c) 2021 Серегина Юлия Витальевна

Институт управления, экономики и финансов Казанский федеральный университет, Россия, Казань

E-mail: julia.seregina@mail.ru

Статья посвящена теоретическим и практическим аспектам внедрения CRM-систем в процессе управления предприятием, а также особенностям цифровизации бизнес-процессов в современных реалиях. Представлены преимущества и угрозы внедрения CRM-систем, а также сравнение популярных программных продуктов.

Ключевые слова: CRM-система, цифровизация производства, управление предприятием, обработка данных, клиентоориентированность, информатизация.

Стремление к повышению лояльности клиентов стоит в основе формирования и обработки достаточно больших объемов данных, поэтому возникает необходимость использования информационных технологий, которые могут осуществить цифровизацию получаемой информации и автоматизировать все процессы, связанные с ее обработкой и анализом.

Данную задачу в части активизации контактов на долгосрочной основе с имеющимися и с потенциальными потребителями можно решить с помощью внедрения концепции CRM-систем (Customer Relationship Management). Она подразумевает применение новейших технологий в сфере управления и получения информации, посредством которых организация может осуществить сбор данных о своих клиентах на каждом этапе взаимоотношений с ними, получить необходимые данные и применить их для развития своей деятельности через построение отношений, которые будут выгодны обеим сторонам. Обратимся к подходам разных ученых к определению понятия CRM-системы и ее роли в деятельности компании.

A.M. Евневич рассматривает CRM-систему как информационную систему внутри компании, которая автоматизирует стратегии взаимодействия с клиентами, в том числе повышает объем продаж, оптимизирует маркетинговую деятельность и улучшает уровень обслуживания потребителей посредством сохранения данных о них и истории взаимодействия с ними, совершенствования бизнес-процессов и дальнейшего их анализа [3, с. 549].

По мнению С.Г. Васина, CRM-системы представляют собой определенный подход к организации и управлению взаимоотношениями между компанией, заказами и потребителями, в котором собираются, хранятся и анализируются данные о партнерах, поставщиках, об имеющихся и потенциальных клиентах предприятия [2, c. 8].

Другую трактовку понятия приводит Н.А. Казакова, которая рассматривает CRM-системы с точки зрения информационных систем, которые вводят, хранят и анализируют информацию об осуществлении отгрузок товаров, оказании услуг, получении денежных средств, сроках выполнения заявок и продвижении деятельности по проекту и многих других задач. Эти данные 
могут вводиться одним из сотрудников или быть импортированы из других информационных систем по принципу автоматизации [4, с. 89]. К.В. Балдин приоритетной целью использования данных систем определяет возможность управления и систематизации данных о заказах [1].

Таким образом, CRM-система является программным продуктом, который включает комплекс взаимосвязанных модулей и нацелен на то, чтобы оптимизировать управление сделками, контролировать и учитывать продукцию, организовывать каналы сбыта, начиная от поставщиков и до конечного клиента [6, с. 116].

CRM-системы на данном этапе цифровизации деятельности предприятий различного масштаба широко применимы и имеют ряд неоспоримых преимуществ.

1. Увеличивается скорость утверждения решения, так как объединяется разрозненная информация о потребителях, сохраняется история взаимодействия с клиентами. CRM-система способствует автоматизации отслеживания значимых событий, которые связаны с конкретным клиентом. Например, CRM-система помогает повысить эффективность использования рабочего времени, проводить автоматизацию коммерческих бизнес-процессов.

2. Процессы маркетинга характеризуются все большей клиентоориентированностью и индивидуальным подходом, так как системы собирают данные о всех потребителях, а также способствуют определению и прогнозированию нужд в ресурсах для взаимодействия с каждым клиентом.

3. Увеличивается степень достоверности отчетов и повышается точность прогнозирования продаж благодаря систематизации информации. За счет этого весь бумажный документооборот трансформируется в электронную форму.

4. CRM-системы могут сочетаться с другими видами систем (электронная почта, корпоративная связь и т.д.).

5. Повышаются качественные характеристики и оперативность обслуживания заявок потребителей за счет доступа к каждому компоненту взаимоотношений с потребителями.

Рассматривая аналитику внедрения популярного онлайн-сервиса Salesforce Sales Cloud за период 2015-2020 гг., можно отметить большое количество новых внедрений в 2015 году и далее два года активной работы CRM-системы. Кризис частично сократил число проектов в 2018 году, однако в среднем за 2015-2020 гг. происходило порядка 250 внедрений в год.

В 2020 году пандемия новой коронавирусной инфекции стала катализатором нового этапа внимания к цифровым помощникам бизнеca. До пандемии основными пользователями CRM-систем были предприятия розничной торговли, финансового сектора и производственные фирмы, во время и после введения режима самоизоляции и удаленной работы использование CRM-системы стало едва ли не единственной возможностью взаимодействия с сотрудниками и клиентами любого предприятия. Динамика новых внедрений по крупнейшим компаниям отличается от общих тенденций. В крупнейших компаниях всплеск внедрений пришелся на 2017 год, далее наблюдался плавный рост числа проектов [7].

В целом, CRM-системы способствуют гармоничному развитию, так как направлены на научно-техническое развитие компании, развивают личность и осуществляют укрепление потенциала для удовлетворения нужд клиентов.

При этом, необходимо привести основные причины недостатков CRM-системы.

1. Заказчики не имеют постоянной возможности осуществлять определение четких задач для CRM-системы. Необходимо на начальном этапе иметь понимание основных особенностей процесса организации, выражать определенные требования, которые вводятся в систему.

2. Может быть произведен неправильный выбор компании разработчика программного продукта, что ведет к дальнейшим значительным тратам.

3. Может быть произведена неправильная постановка задач для системы. На основании конкретных характеристик, которые должна иметь система, требований заказчика, сформулированных задач, нужно произвести выбор системы, которая наиболее органично подходит к конкретной компании. Обратимся в таблице 1 , в которой приведено сравнение основного функционала популярных в России CRM-систем.

Можно говорить о том, что функционал систем Сбер и Битрикс достаточно широк, по сравнению с другими, а возможность групповых чатов дает возможность осуществления коммуникации на достаточно эффективном уровне. Стоимость же зависит от количества пользователей, контактов, открытых сделок, объемов облачного хранилища и других факторов. 
Таблица 1. Сравнение популярных CRM-систем

\begin{tabular}{|l|c|c|c|c|}
\hline \multicolumn{1}{|c|}{ Наименование системы } & СберСРМ & Битрикс 24 & атоСRM & Мегаплан \\
\hline Интеграция & Есть & Есть & Есть & Есть \\
\hline Мобильное приложение & Есть & Есть & Есть & Есть \\
\hline Облако/Сервер & Есть & Есть & Есть/Нет & Есть/Нет \\
\hline Групповые чаты & Есть & Есть & Есть & Нет \\
\hline Аналитика & Есть & Есть & Есть & Нет \\
\hline $\begin{array}{l}\text { Экспорт контактов в CSV, } \\
\text { Ехсеl, Оutlook }\end{array}$ & Есть & Есть & $499-1499$ & $399-9500$ \\
\hline $\begin{array}{l}\text { Стоимость (на одного со- } \\
\text { трудника), руб./мес. }\end{array}$ & оли 550 & $1190-11190$ & & \multirow{2}{*}{} \\
\hline
\end{tabular}

Источник: составлено автором.

4. Некорректный подход к задаче обучения сотрудников работе в CRM-системе. На стадии запуска данного программного обеспечения должно проходить обучение персонала, обладающего высокой квалификацией по работе с данной системой. По причине постоянного обновления системы, необходимо периодически проводить повышение квалификации.

5. В большинстве случаев стоимость внедрения и использования системы достаточно высока, что наиболее ощутимо сказывается на бюджете небольших компаний. Кроме того, необходимо учитывать дополнительные затраты, к которым можно отнести техническую поддержку компании, различные доработки, интегрирующие процессы с разными сервисами, программные обновления и поддержание дополнительного места на диске. Одним из вероятных решений этой проблемы может являться достаточное широкое распространение данных системы во всех сферах предпринимательской деятельности, и, следовательно, понижение стоимости [5, с. 42].

6. Обеспечение безопасности не может также быть полностью гарантировано CRM-системами. Стоит учитывать, что в них содержится полная база клиентов и коммерческие данные.

Можно сделать о том, что внедрение CRM-систем - способ оптимизации многих бизнес-процессов, как внутренних, так и внешних; это необходимость, продиктованная стремлением к цифровизации и созданию условий для удаленной работы независимо от профиля компании. Однако выбор конкретного программного продукта зависит от задач, которые он призван решать, от функционала и стоимости, этот шаг должен соответствовать стратегии организации.

\section{Библиографический список}

1. Балдин К.В., Уткин В.Б. Информационные системы и технологии в экономике: учеб. для вузов. - М.: ЮНИТИ-ДАНА, 2017. - 336 с

2. Васин С.Г. Искусственный интеллект и цифровизация в управлении компанией/С.Г. Васин // Управление. 2019. - № 3 (17). - C. 5-10.

3. Евневич М.А. Клиентоориентированность в цифровой экономике/М.А. Евневич. - М.: Синергия, 2018. $549 \mathrm{c}$.

4. Казакова Н.А. Влияние цифровой экономики на развитие и конкурентоспособность российского финансового сектора/Н.А. Казакова, Н. В. Романова // Финансовый менеджмент. - 2019. - № 1. - С. 86-94.

5. Маймина Э.В., Пузыня Т.А. Особенности и тенденции развития цифровой экономики/Э.В. Маймина, Т.А. Пузыня // Вестник Белгородского университета кооперации, экономики и права. -2020. - № 6 (67). C. 37-45.

6. Townsend A.M. Smart Cities: Big Data, Civic Hackers, and the Quest for New Utopia/Anthony M. Townsend // W.W. Norton\&Company, 2018. - 384 p. 
7. Распределение CRM-проектов по отраслям. - Текст: электронный // TAdviser: [caйт]. - URL: https:// www.tadviser.ru/index.php/\%D0\%A1\%D1\%82\%D0\%B0\%D1\%82\%D1\%8C\%D1\%8F:\%D0\%9E\%D1\%82\%D1\%80\% D0\%B0\%D1\%81\%D0\%BB\%D0\%B5\%D0\%B2\%D0\%B0\%D1\%8F_\%D1\%81\%D0\%BF\%D0\%B5\%D1\%86\%D0\%B8\%D 1\%84\%D0\%B8\%D0\%BA\%D0\%B0_\%D0\%B2\%D0\%BD\%D0\%B5\%D0\%B4\%D1\%80\%D0\%B5\%D0\%BD\%D0\%B8\%D 0\%B9_CRM (дата обращения: 26.01.2022).

8. Mikhailov F.B., Fakhrutdinova E. V., Mefodeva M.A., Yagudin R.K. WORK OPTIMIZATION OF THE PRODUCTION STAFF WHEN IMPLEMENTING TECHNICAL INNOVATIONS// Mediterranean Journal of Social Sciences. 2015. T. 6. № 1 S3. C. $86-90$. 